\title{
Induction Cisplatin and Gemcitabine Versus Cisplatin, Fluorouracil, and Docetaxel in Locoregionally Advanced Nasopharyngeal Carcinoma: a Network Meta-analysis
}

\author{
Qiuji WU ( $\square$ wuqiuji@126.com ) \\ Wuhan University Zhongnan Hospital https://orcid.org/0000-0002-4655-3108 \\ Shaojie Li \\ Wuhan University Second Clinical Hospital: Wuhan University Zhongnan Hospital \\ Jia Liu \\ Wuhan University Second Clinical College: Wuhan University Zhongnan Hospital \\ Yahua Zhong \\ Wuhan University Second Clinical Hospital: Wuhan University Zhongnan Hospital
}

\section{Research}

Keywords: nasopharyngeal carcinoma, induction chemotherapy, network meta-analysis, efficacy, toxicity

Posted Date: November 10th, 2021

DOI: https://doi.org/10.21203/rs.3.rs-1042949/v1

License: (ㄷ) (i) This work is licensed under a Creative Commons Attribution 4.0 International License. Read Full License 


\section{Abstract}

Background and purpose

Cisplatin plus gemcitabine (GP), and cisplatin, fluorouracil plus docetaxel (TPF) has been approved in induction chemotherapy in locoregionally advanced nasopharyngeal carcinoma (LANPC). We compared the clinical outcomes and toxicities of these two regimens by network meta-analysis.

Materials and methods

We systematically searched studies comparing different regimens of IC plus CCRT versus CCRT alone for LANPC. Conventional and Bayesian network meta-analysis were conducted for statistical analysis.

Results

Nine eligible studies with a total of 4,977 patients were involved. Compared with CCRT alone, IC+CCRT significantly improved PFS (HR=0.65 [95\%Cl, 0.54-0.77]) and OS ( $\mathrm{HR}=0.68$ [95\% $\mathrm{Cl}, 0.54-0.85])$ in conventional meta-analysis. In Bayesian network meta-analysis, only TPF and GP improved clinical outcomes significantly. GP showed non-significant trends of superiority over TPF without increasing the incidence of $\geq$ grade 3 adverse events.

Conclusion

Induction GP regimen showed non-significant trends of superiority in terms of clinical outcomes compared with TPF regimen in LANPC.

\section{Introduction}

Nasopharyngeal carcinoma (NPC) is a unique epithelial carcinoma arising from the mucosa of the nasopharynx with distinct geographical distribution. NPC is highly prevalent in South China. The estimated global new cases of NPC in 2020 is 133,354 (0.7\%)[1]. In China, 60,600 new cases were estimated in 2015 with a ratio of about 2.5 between males and females[2]. The outcomes of NPC have been improved substantially with the advance in early disease screen, development of more sensitive diagnostic markers and imaging tools, and the use of optimized chemoradiotherapy. NPC is sensitive to radiotherapy and chemotherapy and he prognosis of NPC has been greatly improved. The five-year overall survival is over $90 \%$ for stage I-II, $83 \%$ for stage III, and 71\% for stage non-metastatic IVa diseases[3].

Induction chemotherapy (IC) with platinum-based chemotherapy followed by concurrent chemoradiotherapy (CCRT) is the standard of care for locoregionally advanced (stage III-IVa) NPC[4]. The addition of IC to CCRT led to significant improved clinical outcomes in terms of progression-free survival, overall survival, locoregional control, and distant control, as compared with CCRT alone in locoregionally advanced NPC[5-7]. Currently, preferred regimens including GP (gemcitabine plus cisplatin, category 1 recommendation), TPF (docetaxel, cisplatin plus 5-fluorouracil, category recommendation for EBV-positive NPC and category 2A for non-EBV-associated NPC) are recommended for IC in NPC. Other choice of IC could be TP (docetaxel plus cisplatin), PF (cisplatin plus 5-fluorouracil), and PX (cisplatin plus capecitabine). The benefit of IC with TPF regimen was shown in a phase III randomized clinical trial (NCT01245959) that allocated 241 patients and 239 patients with locoregionally advanced NPC into the IC plus CCRT group, and the CCRT group, respectively. Compared with CCRT alone, IC plus CCRT led to significantly improved 5-year locoregional failure-free survival (83.8\% versus $90.7 \%, \mathrm{p}=0.044)$, distant failure-free survival $(79.8 \%$ versus $88.0 \%, \mathrm{p}=0.030)$, as well as overall survival $(77.7 \%$ versus $85.6 \%$, $\mathrm{p}=0.042$ ) without adding to late toxicities[8, 9]. Another phase III randomized clinical trial compared CCRT with ( $n=242)$ or without IC ( $n=238)$ using GP regimen (NCT01872962). IC with GP regimen also improved 3-year recurrence-free survival (85.3\% versus 76.5\%, HR=0.51 [95\% Cl, 0.34-0.77], $\mathrm{p}=0.001)$, distant recurrence-free survival $(91.1 \%$ versus $84.4 \%, \mathrm{HR}=0.43$ [95\% $\mathrm{Cl}, 0.25-0.73])$, and overall survival $(94.6 \%$ versus $90.3 \%, \mathrm{HR}=0.43$ [95\% Cl, 0.24-0.77]). Similarly, no obvious increase in late toxicity was noted in the IC plus CCRT group[10].

Although both TPF and GP regimens showed promising effect in combination with CCRT, currently, no study has directly compared the benefit and safety of these regimens. Three-year recurrence-free survival ( $80 \%$ for TPF versus $85.3 \%$ for GP) and overall survival ( $92 \%$ for TPF versus $94.6 \%$ for GP) seemed comparable. Grade 3-4 adverse events such as neutropenia, leucopenia, diarrhea, mucositis were more comment in the IC phase for TPF, while vomiting was more comment for GP. In the CCRT phase, mucositis was more frequently seen for TPF, whereas risk of anemia and thrombocyteopenia was higher for GP[9, 10]. In addition, GP was shown to be cost-effective compared with TPF[11].

Differed from conventional systematic reviews and pairwise meta-analysis that are only capable of comparing two "head-to-head" interventions at a time, network meta-analysis integrates information from all relevant studies, uses statistical methods such as frequentist or Bayesian approach, and thus provides new methods allowing direct and indirect comparison of effectiveness and safety among a network of interventions under the same scenario[12]. Although conclusions should be interpreted with caution due to inherent limitations of network meta-analysis such as potential biases, it could still give valuable information when result from direct comparative study is not available.[13]

In this study, we performed a network meta-analysis to compare the effectiveness and safety profiles of multiple induction chemotherapy regimens in locoregionally advanced NPC with a focus on the comparison of TPF and GP regimens. We aimed to explore the optimal IC regimens and provide potential suggestions for clinical practice. 


\section{Materials And Methods}

\section{Literature search strategy}

We searched published literature from electronic databases including PubMed, Embase and the Cochrane Library for studies that compared different regimens of IC plus CCRT or IC+CCRT versus CCRT in LANPC from Jan 1966 to Jan 2020. We used the following searching equation:

"(((nasopharyngeal carcinoma) OR (nasopharyngeal neoplasms)) OR (nasopharyngeal cancer)) AND (((induction) OR (induction chemotherapy)) OR (neoadjuvant chemotherapy))". No limits were applied to language. Furthermore, published meeting proceedings or abstracts from conferences including those of American Society for Radiation Oncology (ASCO), American Society for Radiation Oncology (ASTRO), European Society for Medical Oncology (ESMO), European Society for Radiotherapy \& Oncology (ESTRO), Asian Clinical Oncology Society, Chinese Society of Clinical Oncology (CSCO), Chinese Society for Radiation Oncology (CSTRO) were consulted. Registered clinical trials were also examined (http://www.clinicaltrials.gov or http://www.who. int/trialsearch).

\section{Literature selection criteria}

We screened randomized clinical trials (RCTs) and observational studies (OBS) to construct the Bayesian network meta-analysis. All included studies were assessed as follows. Inclusion criteria: (1) [P] histologically proven locoregional advanced NPC patients without metastasis; (2) [I] triple or double drug-based IC plus CCRT; (3) [C] cisplatin-based CCRT; (4) [O] OS, PFS and treatment toxicities were reported. Exclusion criteria: (1) singled armed study; (2) studies with inferior quality or high risk of bias; (3) data was not available for analysis; (4) reported outcomes were not of current interest.

\section{Data extraction and collection}

Independently, two researchers (QW and SL) assessed the potential eligibility of the imported records by examining the titles and abstracts, and any divergence would be settled by two other authors ( $\mathrm{JL}$ and $\mathrm{YZ}$ ). A standardized data collection form was adopted to extract and gather publication information, experimental design and outcomes. All the digital index of outcomes were validated and managed by entering into the Review Manger (version 5.4, http:// www.cochrane.org). Above-mentioned procedures had gone through inspection.

\section{Methodological quality assessment}

Before constructing the Bayesian network meta-analysis, a methodological quality assessment was conducted on the included studies. For RCTs, we evaluated the quality from three aspects: 2 points for randomization, 2 points for blinding and 1 point for withdrawals and dropouts, using the Oxford Quality Score (also referred to as the Jadad Score)[14]. A cumulative score $\leq 2$ was regarded as research of low quality, and $\geq 3$ was considered as high quality research. Meanwhile, we assessed the quality of observational studies by using the Newcastle-Ottawa Scale (NOS), which also inspect three aspects of studies: 4 points for selection of objects, 2 points for comparability, and 3 points for measurement. A final score $\leq 5$ was regarded as research of low quality, and $\geq 6$ was considered as high quality research. Ineligible studies would be excluded[15].

\section{Outcomes}

In order to capture all useful information, to reduce the risk of potential bias and to increase the credibility of the results, we set the overall survival rate (OS) at 3 years as the main endpoint, and the progression-free survival rate (PFS) at 3 years, treatment completion rate and $\geq$ grade 3 adverse events (AEs) as secondary endpoints, which were reported in most of the literature.

\section{Statistical Analysis}

We applied the following steps to conduct the statistical analysis. Step 1: A traditional meta-analysis was constructed to compare OS and PFS of ICCCRT vs CCRT. An overall HR $<1$ meant favoring the experimental arm. Step 2: Based on results of step one, we attempted to find out which regimen of IC-CCRT was optimal. So a Bayesian network meta-analysis was created to explore comparable relationships among IC-CCRT regimens by using the package "gemtc" of the software R (MathSoft, version 4.0.3, https://www.r-project.org)[16, 17]. Step 3: Regarding the heterogeneity among included studies, we chose random effects model and assessed the results of heterogeneity by l-square $\left(I^{2}\right)$ and forest plots. Step 4: The NodeSplitting was use to calculate the inconsistency with the model of consistency. And if there were significant inconsistency, we would repeat the step with inconsistent model. Step 5: The final results were visualized by forest plots and rank probability, and a HR $<1$ or the highest bar located in far left meant favorable.

\section{Results}

\section{Study search and selection}

After preliminary screening by reading article titles and abstracts, we included 17 articles for further assessment by reading full text and evaluating risk of bias. Finally, 9 of these 17 articles covering 4,977 patients were selected for subsequent statistical analysis, which contained 7 RCTs[10, 1823] and 2 OBS[24, 25] (Figure 1). 
Main characteristics of the 9 studies were summarized in Table 1. There were 7 RCTs, published from 2009 to 2019 , involving 6 kinds of induction chemotherapies (namely, TP, docetaxel and cis-platinum; TPE, paclitaxel, epirubicin and cis-platinum; TGP, paclitaxel, gemcitabine and carboplatin; TPF, docetaxel, cis-platinum and fluorouracil; PF, cis-platinum and fluorouracil; GP, gemcitabine and cis-platinum). The two were OBS that assessed TPF+CCRT versus GP+CCRT, and TPF+CCRT versus PF+CCRT versus TP+CCRT, respectively. Additionally, the latter observational study (Peng et al. 2018) involved 3 different IC regimens (TPF, PF and TP), so we reused TPF to compared with PF and TP. The median follow-up time was from 3.4 years to 4.6 years. All studies had been assessed to have high methodological quality (the Jadad Score $\geq 3$ or the NOS $\geq 6$ ) (Table 1 ).

\section{Quality assessment}

The analysis of both OS and PFS had acceptable heterogeneity (PFS: $I^{2}=0 \%$; OS: $I^{2}=47 \%$ ). The bias of publication was visualized by funnel plots. The scatters distributed evenly on both sides of the dotted lines in the two plots (Figure 2), indicating that the bias of the meta-analysis was acceptable.

We chose the random model and set the number of iterations as 50000 with other default options to construct the Bayesian network meta-analysis

(Figure 3). Trace plots, density plots (Figure S1凶S2) and the results of convergence diagnostics (Figure S3凶S4) showed the stated iterations was adequate. In the heterogeneity test, most of data did not show significant heterogeneity, except that of the overall survival data about TP+CCRT versus CCRT $\left(I^{2}=60.4 \%\right)$ (Figure S5). Given that we mainly focused on comparing GP and TPF as induction chemotherapy, we thought this heterogeneity influenced little the results. The consistency test showed that there was no significant difference between direct and indirect comparisons for PFS and OS (Figure S6).

\section{Conventional meta-analysis}

Progression-free survival

PFS was significantly improved by IC+CCRT (HR=0.65 [95\% Cl, 0.54-0.77]), and other regimens, except TPF+CCRT and GP+CCRT, had insignificant influence to the overall effect (Figure 4A).

Overall survival

The results of the meta-analysis showed IC+CCRT significantly improved OS compared with CCRT alone (HR=0.68 [95\%Cl, 0.54-0.85]). Meanwhile, TPF+CCRT, GP+CCRT and TP+CCRT contributed to the overall effect significantly. (Figure 4B).

\section{Bayesian network meta-analysis}

Progression-free survival

Conventional meta-analysis demonstrated that only TPF and GP improved both PFS and OS significantly, In order to find out which IC regimen was optimal based on the existing evidence, we constructed the Bayesian network meta-analysis. The results of the Bayesian network meta-analysis showed that compared with CCRT alone, GP+CCRT (HR=0.50 [95\% Cl, 0.27-0.87]) and TPF+CCRT (HR=0.56 [95\%Cl, 0.36-0.81]) significantly improved PFS (Figure 5A). GP showed a slight tendency of superiority over TPF (HR=0.89 [95\% Cl, 0.48-1.7]), which was not statistically significant. Meanwhile, other regimens showed tendency to be inferior to TPF+CCRT in terms of improving PFS (Figure 5B, 5C).

\section{Overall survival}

Similar to the analysis of PFS, OS was significantly improved by $\mathrm{GP}+\mathrm{CCRT}(\mathrm{HR}=0.40$ [95\% $\mathrm{Cl}, 0.16-0.94])$ and TPF+CCRT (HR=0.51 [95\%Cl, 0.26-0.88]), while other regimens had non-significant advantage (Figure 6A). Compared with TPF, GP showed a non-significant advantage in improving OS $(\mathrm{HR}=0.80$ [95\% Cl, 0.33-2.0]) (Figure 6B). The rank probability map also indicated that GP might be superior to TPF (Figure 6C). Therefore, current indirect evidence did not support significant difference between GP and TPF in terms of OS, although GP showed a slight tendency of superiority.

\section{Treatment-related adverse events}

The treatment-related toxicities might interrupt the treatment, mitigate the efficacy, or lower the quality of life of patients. We asked whether GP was superior to TPF in terms of treatment-related adverse events. We collected data of grade 3 and 4 adverse events, and found there was no difference in the incidence of severe adverse events (Figure 7). However the incidence of hematological toxicity, such as the most common leukopenia, GP was seem to be less than TPF (RR=0.55 [95\% Cl, 0.18-1.8]) (Figure 8).

\section{Table 1 Study characteristics}




\begin{tabular}{|c|c|c|c|c|c|c|c|c|c|c|}
\hline $\begin{array}{l}\text { Frist } \\
\text { author } \\
\text { (year) }\end{array}$ & $\begin{array}{l}\text { Study } \\
\text { type }\end{array}$ & $\begin{array}{l}\text { Study } \\
\text { design }\end{array}$ & $\begin{array}{l}\text { Trial } \\
\text { phase }\end{array}$ & $\begin{array}{l}\text { Cancer } \\
\text { stage }\end{array}$ & $\begin{array}{l}\text { Induction } \\
\text { chemotherapy }\end{array}$ & $\begin{array}{l}\text { Concurrent } \\
\text { chemotherapy }\end{array}$ & $\begin{array}{l}\mathrm{RT} \\
\text { regimen }\end{array}$ & $\begin{array}{l}\text { Patient } \\
\text { number } \\
\text { (treatment/ } \\
\text { control) }\end{array}$ & $\begin{array}{l}\text { Median } \\
\text { follow- } \\
\text { up } \\
\text { (years) }\end{array}$ & $\begin{array}{l}\text { Quality } \\
\text { assessment }\end{array}$ \\
\hline $\begin{array}{l}\text { Hui } \\
(2009) \\
{[21]}\end{array}$ & RCT & $\begin{array}{l}\text { TP + } \\
\text { CCRT } \\
\text { vs } \\
\text { CCRT }\end{array}$ & $\|$ & $\begin{array}{l}\text { III-IVB } \\
\text { (AJCC 5th) }\end{array}$ & $\begin{array}{l}\text { CDDP } 75 \\
\mathrm{mg} / \mathrm{m}^{2} \text {, } \\
\text { docetaxel } 75 \\
\mathrm{mg} / \mathrm{m}^{2} \mathrm{D} 1, \\
\text { q3w *2 } \\
\text { cycles }\end{array}$ & $\begin{array}{l}\text { CDDP } 40 \\
\mathrm{mg} / \mathrm{m}^{2} \\
\mathrm{q} 1 \mathrm{w} * 8 \\
\text { weeks }\end{array}$ & $\begin{array}{l}66 \\
\text { Gy/33 F }\end{array}$ & $34 / 31$ & 4.3 & 3 (Jadad) \\
\hline $\begin{array}{l}\text { Fountzilas } \\
(2012) \\
{[19]}\end{array}$ & RCT & $\begin{array}{l}\text { TPE + } \\
\text { CCRT } \\
\text { Vs } \\
\text { CCRT }\end{array}$ & II & $\begin{array}{l}\text { IIB-IVB } \\
\text { (AJCC 6th) }\end{array}$ & $\begin{array}{l}\text { CDDP } \\
75 \mathrm{mg} / \mathrm{m}^{2} \mathrm{D} 2, \\
\text { epirubicin } \\
75 \mathrm{mg} / \mathrm{m}^{2} \mathrm{D} 1, \\
\text { paclitaxel } \\
175 \mathrm{mg} / \mathrm{m}^{2} \\
\text { D } 1 \mathrm{q} 3 \mathrm{w} * 3 \\
\text { cycles }\end{array}$ & $\begin{array}{l}\text { CDDP } 40 \\
\mathrm{mg} / \mathrm{m}^{2} \\
\mathrm{q} 1 \mathrm{w} * 7 \\
\text { weeks }\end{array}$ & $\begin{array}{l}66-70 \\
\text { Gy/33- } \\
35 \mathrm{~F}\end{array}$ & $72 / 69$ & 4.6 & 3 (Jadad) \\
\hline $\begin{array}{l}\text { Tan } \\
(2015) \\
{[23]}\end{array}$ & RCT & $\begin{array}{l}\text { TGP + } \\
\text { CCRT } \\
\text { vs } \\
\text { CCRT }\end{array}$ & II-III & $\begin{array}{l}\text { III-IVB } \\
\text { (AJCC 5th) }\end{array}$ & $\begin{array}{l}\text { Gemcitabine } \\
1000 \mathrm{mg} / \mathrm{m}^{2}, \\
\text { carboplatin } \\
\text { AUC } 2.5, \\
\text { paclitaxel } 70 \\
\mathrm{mg} / \mathrm{m}^{2} \mathrm{D} 1 \\
\text { and } 8, \mathrm{q}^{2} \mathrm{w} * 3 \\
\text { cycles }\end{array}$ & $\begin{array}{l}\text { CDDP } 40 \\
\mathrm{mg} / \mathrm{m}^{2} \\
\mathrm{q} 1 \mathrm{w} * 8 \\
\text { weeks }\end{array}$ & $\begin{array}{l}69.96 \\
\text { Gy } / 33 \mathrm{~F} \\
\text { (IMRT) } \\
70 \\
\text { Gy/35 F } \\
\text { (2D) }\end{array}$ & $92 / 88$ & 3.4 & 3 (Jadad) \\
\hline $\begin{array}{l}\text { Sun } \\
(2016) \\
{[22]}\end{array}$ & RCT & $\begin{array}{l}\text { TPF + } \\
\text { CCRT } \\
\text { vs } \\
\text { CCRT }\end{array}$ & III & $\begin{array}{l}\text { III-IVB } \\
\text { (except T3- } \\
\text { 4N0) } \\
\text { (AJCC 7th) }\end{array}$ & $\begin{array}{l}\text { Docetaxel, } 60 \\
\mathrm{mg} / \mathrm{m}^{2} \mathrm{D} 1, \\
\mathrm{CDDP} 60 \mathrm{mg} / \\
\mathrm{m}^{2} \mathrm{D} 1, \\
5-\mathrm{FU} 600 \\
\mathrm{mg} / \mathrm{m}^{2} \mathrm{D} 1 \text { to } \\
\mathrm{D} 5, \\
\mathrm{q} 3 \mathrm{w} \text { *3 } \\
\text { cycles }\end{array}$ & $\begin{array}{l}\text { CDDP } 100 \\
\mathrm{mg} / \mathrm{m}^{2} \\
\mathrm{q} 3 \mathrm{w} * 3 \\
\text { cycles }\end{array}$ & $\begin{array}{l}\geq 66 \\
\text { Gy } \\
2.00- \\
2.27 \\
\text { Gy/F }\end{array}$ & $241 / 239$ & 3.8 & 3 (Jadad) \\
\hline $\begin{array}{l}\text { Cao } \\
(2017) \\
{[18]}\end{array}$ & RCT & $\begin{array}{l}\text { PF + } \\
\text { CCRT } \\
\text { vs } \\
\text { CCRT }\end{array}$ & III & $\begin{array}{l}\text { III-IVB } \\
\text { (except } \\
\text { T3NO-1) } \\
\text { (AJCC 6th) }\end{array}$ & $\begin{array}{l}\text { CDDP } 80 \\
\mathrm{~g} / \mathrm{m}^{2} \mathrm{D} 1, \\
5-\mathrm{FU} 800 \\
\mathrm{mg} / \mathrm{m}^{2} \mathrm{D} 1 \text { to } \\
\text { D5, q3w * } 2 \\
\text { cycles }\end{array}$ & $\begin{array}{l}\text { CDDP } 80 \\
\mathrm{mg} / \mathrm{m}^{2} \\
\mathrm{q} 3 \mathrm{w} * 3 \\
\text { cycles }\end{array}$ & $\begin{array}{l}70 \text { Gy } \\
2.00- \\
2.27 \\
\text { Gy/F }\end{array}$ & $238 / 238$ & 4.2 & 3 (Jadad) \\
\hline $\begin{array}{l}\text { Frikha } \\
(2018) \\
{[20]}\end{array}$ & RCT & $\begin{array}{l}\text { TPF + } \\
\text { CCRT } \\
\text { vs } \\
\text { CCRT }\end{array}$ & III & $\begin{array}{l}\text { IIB-IVB } \\
\text { (AJCC 6th) }\end{array}$ & $\begin{array}{l}\text { Docetaxel, } 75 \\
\mathrm{mg} / \mathrm{m}^{2} \mathrm{D} 1, \\
\mathrm{CDDP} 75 \\
\mathrm{mg} / \mathrm{m}^{2} \mathrm{D} 1, \\
5-\mathrm{FU} 750 \\
\mathrm{mg} / \mathrm{m}^{2} \mathrm{D} 1 \text { to } \\
\mathrm{D} 5, \\
\mathrm{q} 3 \mathrm{w} * 3 \\
\text { cycles }\end{array}$ & $\begin{array}{l}\text { CDDP } 40 \\
\mathrm{mg} / \mathrm{m}^{2} \\
\mathrm{q} 1 \mathrm{w} * 7 \\
\text { weeks }\end{array}$ & $\begin{array}{l}70 \\
\text { Gy/35 F }\end{array}$ & $41 / 40$ & 3.6 & 3 (Jadad) \\
\hline $\begin{array}{l}\text { Zhang } \\
(2019) \\
{[10]}\end{array}$ & RCT & $\begin{array}{l}\text { GP + } \\
\text { CCRT } \\
\text { vs } \\
\text { CCRT }\end{array}$ & III & $\begin{array}{l}\text { III-IVB } \\
\text { (except } \\
\text { bulky } \\
\text { primary } \\
\text { tumor N0) } \\
\text { (AJCC 7th) }\end{array}$ & $\begin{array}{l}\text { Gemcitabine, } \\
1000 \mathrm{mg} / \mathrm{m}^{2} \\
\text { D1 and D8, } \\
\text { CDDP } 80 \mathrm{mg} / \\
\mathrm{m}^{2} \mathrm{D} 1, \\
\text { q3w * } 3 \\
\text { cycles }\end{array}$ & $\begin{array}{l}\text { CDDP } 100 \\
\mathrm{mg} / \mathrm{m}^{2} \\
\mathrm{q} 3 \mathrm{w} * 3 \\
\text { cycles }\end{array}$ & $\begin{array}{l}66-70 \\
\text { Gy/30- } \\
33 \mathrm{~F}\end{array}$ & $242 / 238$ & 3.6 & 3 (Jadad) \\
\hline $\begin{array}{l}\text { Zeng } \\
\text { (2018) } \\
{[25]}\end{array}$ & OBS & $\begin{array}{l}\text { TPF + } \\
\text { CCRT } \\
\text { vs GP }\end{array}$ & 1 & $\begin{array}{l}\text { III-IV with } \\
\text { non-distant } \\
\text { metastases }\end{array}$ & $\begin{array}{l}\text { Docetaxel, } 60 \\
\mathrm{mg} / \mathrm{m}^{2} \mathrm{D} 1\end{array}$ & $\begin{array}{l}\text { CDDP } 80 \\
\mathrm{mg} / \mathrm{m}^{2}\end{array}$ & $\begin{array}{l}66-74 \\
\text { Gy/33- } \\
35 \mathrm{~F}\end{array}$ & $58 / 55$ & 4.3 & 6 (NOS) \\
\hline
\end{tabular}




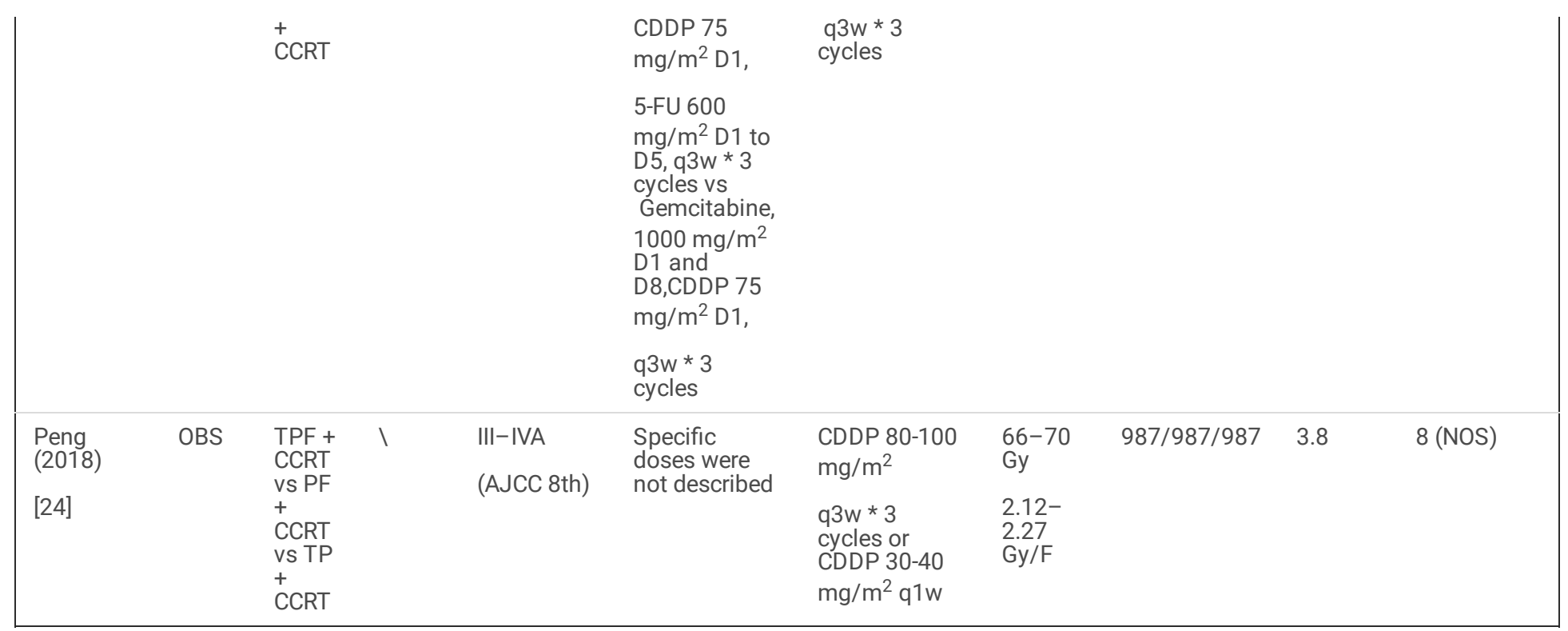

Abbreviations: 5-FU, 5-fluorocrail; AJCC『American Joint Committee on Cancer囚CCRT囚concurrent chemoradiotherapy; CDDP, cis-platinum; OBS, observational study; NOS, the Newcastle-Ottawa Scale; RCT, randomized clinical trial; RT, radiotherapy.

\section{Discussion}

In this study, we applied network meta-analysis to compare the effectiveness and safety profiles among multiple induction chemotherapy regimens for locoregionally advanced NPC. We involved GP, PF, TP, TGP, TPF, TPE regimens and paid specific attention on GP and TPF regimens. We found that only GP and TPF were associated with both improved progression-free survival and overall survival without marked increase in treatment-associated toxicities, while other regimens did not show statistically significant survival benefit. In addition, our study indicated that, although non statistically different, GP seemed superior to TPF in terms of PFS ( $\mathrm{HR}=0.89[95 \% \mathrm{Cl}, 0.48-1.7])$ and $\mathrm{OS}(\mathrm{HR}=0.8[95 \% \mathrm{Cl}, 0.33-2.0])$. These results suggest that GP and TPF are favorable regimens in IC for locoregionally advanced NPC, and comparative studies between these two regimens are needed.

Concurrent chemoradiotherapy was established as mainstay for locoregionally advanced NPC[26, 27]. Numerous studies have since then explored the benefit of adding induction chemotherapy. Regimens such as PF[18, 28], TP[21, 29], PX[30], and others[31, 32] have been investigated as IC protocols. While improved failure-free survival was reported in these phase II or phase III trials, whether there was a benefit in overall survival was debated[5, 6, 33, 34]. Clear benefit in both failure-free survival and overall survival was obtained in two recent phase III randomized trials that evaluated the effectiveness and safety of IC with TPF[8, 9] or GP[10, 35], respectively, plus CCRT, compared with CCRT alone. In both studies, clear improvement in failure-free survival (TPF plus CCRT $77.4 \%$ versus CCRT alone $66.4 \%$ in 5 years; GP plus CCRT $85.3 \%$ versus CCRT alone $76.5 \%$ in 3 years), distant failure-free survival (TPF plus CCRT $88.0 \%$ versus CCRT alone $79.8 \%$ in 5 years; GP plus CCRT $91.1 \%$ versus CCRT alone $84.4 \%$ in 3 years), and overall survival (TPF plus CCRT $88.0 \%$ versus CCRT alone $77.7 \%$ in 5 years; GP plus CCRT $94.6 \%$ versus CCRT alone $90.3 \%$ in 3 years) was observed. We noted that there might be difference in terms of treatment-associated toxicities and patient compliance. For example, although $88 \%$ of patients in the TPF plus CCRT group completed planed three cycles of IC, only $30 \%$ of these patients completed three cycles of concurrent cisplatin, compared with $56 \%$ in the CCRT alone group. Note that for IC with GP, only $38.9 \%$ of patients completed planed three cycles of IC and only $79.9 \%$ of patients in the IC plus CCRT received at least $200 \mathrm{mg} / \mathrm{m}^{2}$ of concurrent cisplatin, contrasted with $95.8 \%$ in the CCRT alone group. However, no randomized study performing direct comparison between TPF and GP as IC regimens is available.

There are some retrospective studies with limited number of patients that compared selected IC regimens. Zang et al. retrospectively compared GP versus TP as IC regimens in locoregionally advanced NPC and found that GP was better than TP in terms of DFS (HR=0.47 [95\%Cl, 0.26-0.85], $\mathrm{p}=0.036)$, LRFS $(\mathrm{HR}=0.23$ [95\% $\mathrm{Cl}, 0.09-0.58], \mathrm{p}=0.03)$, but the improvement in OS $(\mathrm{HR}=0.52$ [95\% $\mathrm{Cl}, 0.26-1.03], \mathrm{p}=0.13)$ was not statistically significant[36]. This finding was in line with our results. Another retrospective study by Zhu et al. indicated that both GP and TPF combined with CCRT significantly improve DFS and OS in NPC patients compared with CCRT alone. GP showed comparable effectiveness but few grade 3-4 toxicities than TPF[37]. Another study showed similar results[25]. These data are in accordance with our findings. Specifically, we found that only induction TPF and GP improved both patients' progression-free survival and overall survival as compared with CCRT alone. However, other regimens seemed not resulted in clear improvement in patient survival. Although GP showed tendency to perform better than TPF, this effect was not statistically different. There was no difference in treatment-related toxicities between these groups.

Nevertheless, up to date, few prospective randomized trials that directly compare different IC regimens are reported. Given differed duration of hospitalization, requirement of central vena catheterization, treatment-related toxicities, patient compliance, potentially differed quality of life, and differed medical expense, there is a realistic demand in determining which IC regimen is an optimal one for locoregional advanced NPC. Currently, a 
number of trials are still ongoing, including TPC versus PF (NCT02940925), GP versus TPF (NCT02016417, NCT03723343), GP versus PF (NCT03840421), and others. These trials might give critical information on which IC regimen would be an optimal one.

Recently, immunotherapy and in particular immune checkpoint inhibitor treatment, has achieved evolutionally success in a number of solid cancers[38]. In recurrent and metastatic nasopharyngeal carcinoma, immune checkpoint inhibitor combined with conventional chemotherapy led to significant improvement in tumor response and patient survival[39-41]. It is expected that immunotherapy might also show advantage in LANPC. Immunotherapy might increase the response rate of IC and might be active even as single treatment. Two single-armed phase II clinical trial that test the role of induction anti-PD-1 antibodies (Sintilimab, NCT03619824; Toripalimab, NCT04446663) with chemotherapy in LANPC is ongoing. These studies, in addition to the recent advance in induction chemotherapy in LANPC, might bring more novel choices for clinical practice.

There were some limitations in our study. With limited prospective studies in this area, our results were obtained from relatively small number of participants, which may lead to section bias and reduce its generalizability. Although we made indirect comparison among different IC regimens and between GP and TPF using network meta-analysis, these results still could not provide direct evidence on which would be the optimal IC regimen. Therefore, while our study could bring several valuable clues for clinical practice, more prospective studies are needed.

In conclusion, our study indicated that both GP and TPF are favorable IC regimens in LANPC in terms of clinical benefit and safety profiles based on current evidence. Direct comparison between these two regimens in a prospective study might better help determine which one is optimal.

\section{Abbreviations}

AEs: adverse events; ASCO: American Society for Radiation Oncology; ASTRO : American Society for Radiation Oncology ; CCRT: concurrent chemoradiotherapy; Cl: confidence interval; CSCO : Chinese Society of Clinical Oncology ; CSTRO : Chinese Society for Radiation Oncology ; ESMO : European Society for Medical Oncology ; ESTRO : European Society for Radiotherapy \& Oncology ;GP: cisplatin plus gemcitabine; HR: hazard ratio; IC: induction chemotherapy; LANPC: locoregionally advanced nasopharyngeal carcinoma; NOS: the Newcastle-Ottawa Scale; NPC: nasopharyngeal carcinoma; OBS: observational study; OS: overall survival; PF: cisplatin plus 5-fluorouracil; PFS: progression-free survival; PX: cisplatin plus capecitabine; RR: relative risk; RCT: randomized clinical trial; TGP: paclitaxel, gemcitabine and carboplatin; TP: docetaxel plus cisplatin; TPE: paclitaxel, epirubicin and cis-platinum; TPF: cisplatin, fluorouracil plus docetaxel.

\section{Declarations}

\section{Author contribution}

Conceptualization, Qiuji Wu, Shaojie Li, and Yahua Zhong; Methodology, Qiuji Wu, Shaojie Li, and Yahua Zhong; Software and data analysis, Qiuji Wu, Jia Liu and Shaojie Li; Validation, Qiuji Wu, Shaojie Li, Jia Liu, and Yahua Zhong; Writing, review and editing, Qiuji Wu, Shaojie Li, Jia Liu, and Yahua Zhong; Supervision, Yahua Zhong. All authors have read and agreed to the published version of the manuscript.

\section{Funding}

This study was supported by a grant from the Scientific Research Project of Hubei Provincial Health and Family Planning Commission (Grant No. WJ2019H060), a grant from the Leading Discipline Construction Project of Oncology of Zhongnan Hospital of Wuhan University, and a grant from the Science, Technology and Innovation Seed Fund of Zhongnan Hospital of Wuhan University (Grant no. znpy2018123).

\section{Acknowledgement}

We would like to acknowledge the Scientific Research Project of Hubei Provincial Health and Family Planning Commission for their support in our study.

\section{Competing interests}

The authors declare no competing interests.

\section{Ethics approval and consent to participate}

Not applicable.

\section{Consent for publication}

All the authors consent the publication of this work.

\section{Availability of data and materials}

The data and materials in the article are all available. 


\section{References}

1 Sung H, Ferlay J, Siegel RL, et al. Global cancer statistics 2020: Globocan estimates of incidence and mortality worldwide for 36 cancers in 185 countries. CA Cancer J Clin 2021;71:209-249.

2 Chen W, Zheng R, Baade PD, et al. Cancer statistics in china, 2015. CA Cancer J Clin 2016;66:115-132.

3 Pan JJ, Ng WT, Zong JF, et al. Proposal for the 8th edition of the ajcc/uicc staging system for nasopharyngeal cancer in the era of intensitymodulated radiotherapy. Cancer 2016;122:546-558.

4 Chen YP, Ismaila N, Chua MLK, et al. Chemotherapy in combination with radiotherapy for definitive-intent treatment of stage ii-iva nasopharyngeal carcinoma: Csco and asco guideline. J Clin Oncol 2021;39:840-859.

5 Yang SS, Guo JG, Liu JN, et al. Effect of induction chemotherapy in nasopharyngeal carcinoma: An updated meta-analysis. Front Oncol 2020;10:591205.

6 Chen YP, Tang LL, Yang Q, et al. Induction chemotherapy plus concurrent chemoradiotherapy in endemic nasopharyngeal carcinoma: Individual patient data pooled analysis of four randomized trials. Clin Cancer Res 2018;24:1824-1833.

$7 \quad$ Tang M, Jia Z, Zhang J. The evaluation of adding induction chemotherapy to concurrent chemoradiotherapy for locally advanced nasopharyngeal carcinoma: A meta-analysis. Eur Arch Otorhinolaryngol 2021;278:1545-1558.

8 Li WF, Chen NY, Zhang N, et al. Concurrent chemoradiotherapy with/without induction chemotherapy in locoregionally advanced nasopharyngeal carcinoma: Long-term results of phase 3 randomized controlled trial. Int J Cancer 2019;145:295-305.

9 Sun Y, Li WF, Chen NY, et al. Induction chemotherapy plus concurrent chemoradiotherapy versus concurrent chemoradiotherapy alone in locoregionally advanced nasopharyngeal carcinoma: A phase 3, multicentre, randomised controlled trial. Lancet Oncol 2016;17:1509-1520.

10 Zhang Y, Chen L, Hu GQ, et al. Gemcitabine and cisplatin induction chemotherapy in nasopharyngeal carcinoma. N Engl J Med 2019;381:1124-1135.

11 Wu Q, Liao W, Huang J, et al. Cost-effectiveness analysis of gemcitabine plus cisplatin versus docetaxel, cisplatin and fluorouracil for induction chemotherapy of locoregionally advanced nasopharyngeal carcinoma. Oral Oncol 2020;103:104588.

12 Tonin FS, Rotta I, Mendes AM, et al. Network meta-analysis: A technique to gather evidence from direct and indirect comparisons. Pharm Pract (Granada) 2017;15:943.

13 Catala-Lopez F, Tobias A, Cameron C, et al. Network meta-analysis for comparing treatment effects of multiple interventions: An introduction. Rheumatol Int 2014;34:1489-1496.

14 Jadad AR, Moore RA, Carroll D, et al. Assessing the quality of reports of randomized clinical trials: Is blinding necessary? Control Clin Trials $1996 ; 17: 1-12$.

15 Cumpston M, Li T, Page MJ, et al. Updated guidance for trusted systematic reviews: A new edition of the cochrane handbook for systematic reviews of interventions. Cochrane Database Syst Rev 2019;10:ED000142.

16 Shim SR, Kim SJ, Lee J, et al. Network meta-analysis: Application and practice using r software. Epidemiol Health 2019;41:e2019013.

17 Neupane B, Richer D, Bonner AJ, et al. Network meta-analysis using r: A review of currently available automated packages. PLoS One 2014;9:e115065.

18 Cao SM, Yang Q, Guo L, et al. Neoadjuvant chemotherapy followed by concurrent chemoradiotherapy versus concurrent chemoradiotherapy alone in locoregionally advanced nasopharyngeal carcinoma: A phase iii multicentre randomised controlled trial. Eur J Cancer 2017;75:14-23.

19 Fountzilas G, Ciuleanu E, Bobos M, et al. Induction chemotherapy followed by concomitant radiotherapy and weekly cisplatin versus the same concomitant chemoradiotherapy in patients with nasopharyngeal carcinoma: A randomized phase ii study conducted by the hellenic cooperative oncology group (hecog) with biomarker evaluation. Ann Oncol 2012;23:427-435.

20 Frikha M, Auperin A, Tao Y, et al. A randomized trial of induction docetaxel-cisplatin-5fu followed by concomitant cisplatin-rt versus concomitant cisplatin-rt in nasopharyngeal carcinoma (gortec 2006-02). Ann Oncol 2018;29:731-736.

21 Hui EP, Ma BB, Leung SF, et al. Randomized phase ii trial of concurrent cisplatin-radiotherapy with or without neoadjuvant docetaxel and cisplatin in advanced nasopharyngeal carcinoma. J Clin Oncol 2009;27:242-249. 

locoregionally advanced nasopharyngeal carcinoma: A phase 3, multicentre, randomised controlled trial. The Lancet Oncology 2016;17:1509-1520.

23 Tan T, Lim WT, Fong KW, et al. Concurrent chemo-radiation with or without induction gemcitabine, carboplatin, and paclitaxel: A randomized, phase 2/3 trial in locally advanced nasopharyngeal carcinoma. Int J Radiat Oncol Biol Phys 2015;91:952-960.

24 Peng H, Tang LL, Chen BB, et al. Optimizing the induction chemotherapy regimen for patients with locoregionally advanced nasopharyngeal carcinoma: A big-data intelligence platform-based analysis. Oral Oncol 2018;79:40-46.

25 Zeng Z, Yan RN, Tu L, et al. Assessment of concurrent chemoradiotherapy plus induction chemotherapy in advanced nasopharyngeal carcinoma: Cisplatin, fluorouracil, and docetaxel versus gemcitabine and cisplatin. Sci Rep 2018;8:15581.

26 Al-Sarraf M, LeBlanc M, Giri PG, et al. Chemoradiotherapy versus radiotherapy in patients with advanced nasopharyngeal cancer: Phase iii randomized intergroup study 0099. J Clin Oncol 1998;16:1310-1317.

27 Blanchard P, Lee A, Marguet S, et al. Chemotherapy and radiotherapy in nasopharyngeal carcinoma: An update of the mac-npc meta-analysis. Lancet Oncol 2015;16:645-655.

28 Yang Q, Cao SM, Guo L, et al. Induction chemotherapy followed by concurrent chemoradiotherapy versus concurrent chemoradiotherapy alone in locoregionally advanced nasopharyngeal carcinoma: Long-term results of a phase iii multicentre randomised controlled trial. Eur $\mathrm{J}$ Cancer 2019;119:87-96.

29 Zhong YH, Dai J, Wang XY, et al. Phase ii trial of neoadjuvant docetaxel and cisplatin followed by intensity-modulated radiotherapy with concurrent cisplatin in locally advanced nasopharyngeal carcinoma. Cancer Chemother Pharmacol 2013;71:1577-1583.

30 Lee AWM, Ngan RKC, Ng WT, et al. Npc-0501 trial on the value of changing chemoradiotherapy sequence, replacing 5-fluorouracil with capecitabine, and altering fractionation for patients with advanced nasopharyngeal carcinoma. Cancer 2020;126:3674-3688.

31 Hong RL, Hsiao CF, Ting LL, et al. Final results of a randomized phase iii trial of induction chemotherapy followed by concurrent chemoradiotherapy versus concurrent chemoradiotherapy alone in patients with stage iva and ivb nasopharyngeal carcinoma-taiwan cooperative oncology group (tcog) 1303 study. Ann Oncol 2018;29:1972-1979.

32 Frikha M, Auperin A, Tao Y, et al. A randomized trial of induction docetaxel-cisplatin-5fu followed by concomitant cisplatin-rt versus concomitant cisplatin-rt in nasopharyngeal carcinoma (gortec 2006-02). Ann Oncol 2018;29:731-736.

33 Gabani P, Barnes J, Lin AJ, et al. Induction chemotherapy in the treatment of nasopharyngeal carcinoma: Clinical outcomes and patterns of care. Cancer Med 2018;7:3592-3603.

34 OuYang PY, Zhang XM, Qiu XS, et al. A pairwise meta-analysis of induction chemotherapy in nasopharyngeal carcinoma. Oncologist 2019;24:505-512.

35 Zhang Y, Sun Y, Ma J. Induction gemcitabine and cisplatin in locoregionally advanced nasopharyngeal carcinoma. Cancer Commun (Lond) 2019;39:39.

36 Zang J, Xu M, Li C, et al. Gemcitabine and cisplatin versus docetaxel and cisplatin as induction chemotherapy followed by concurrent chemoradiotherapy in locoregionally advanced nasopharyngeal carcinoma from non-endemic area of china. J Cancer Res Clin Oncol 2020;146:23692378.

37 Zhu J, Duan B, Shi H, et al. Comparison of gp and tpf induction chemotherapy for locally advanced nasopharyngeal carcinoma. Oral Oncol 2019;97:37-43.

38 Yang Y. Cancer immunotherapy: Harnessing the immune system to battle cancer. J Clin Invest 2015;125:3335-3337.

39 Fang W, Yang Y, Ma Y, et al. Camrelizumab (shr-1210) alone or in combination with gemcitabine plus cisplatin for nasopharyngeal carcinoma: Results from two single-arm, phase 1 trials. Lancet Oncol 2018;19:1338-1350.

40 Mai HQ, Chen QY, Chen D, et al. Toripalimab or placebo plus chemotherapy as first-line treatment in advanced nasopharyngeal carcinoma: A multicenter randomized phase 3 trial. Nat Med 2021;27:1536-1543.

41 Yang Y, Qu S, Li J, et al. Camrelizumab versus placebo in combination with gemcitabine and cisplatin as first-line treatment for recurrent or metastatic nasopharyngeal carcinoma (captain-1st): A multicentre, randomised, double-blind, phase 3 trial. Lancet Oncol 2021;22:1162-1174.

\section{Figures}




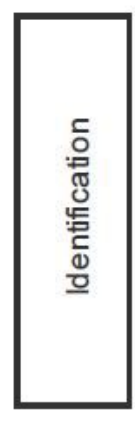

Records identified through databases $(n=2687)$

Additional records identified through other sources $(n=0)$
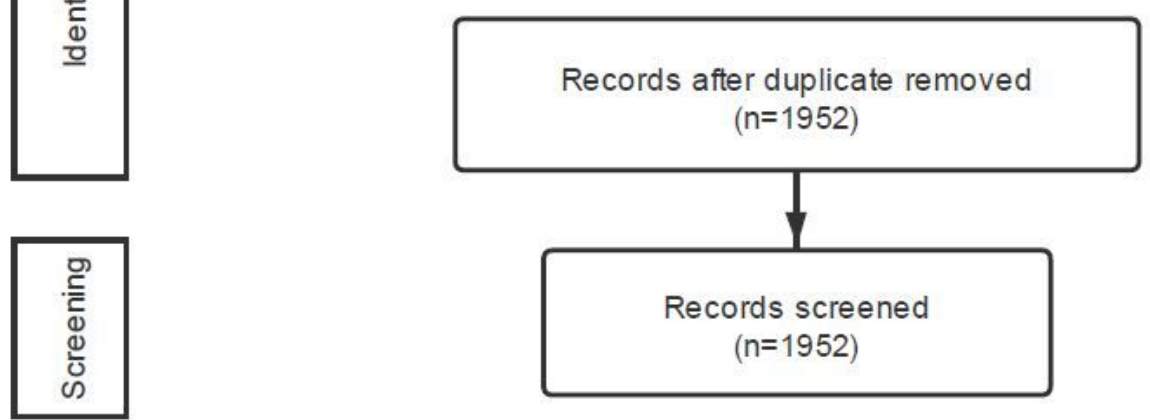
Records excluded after searching
titles and abstracts $(n=1935)$
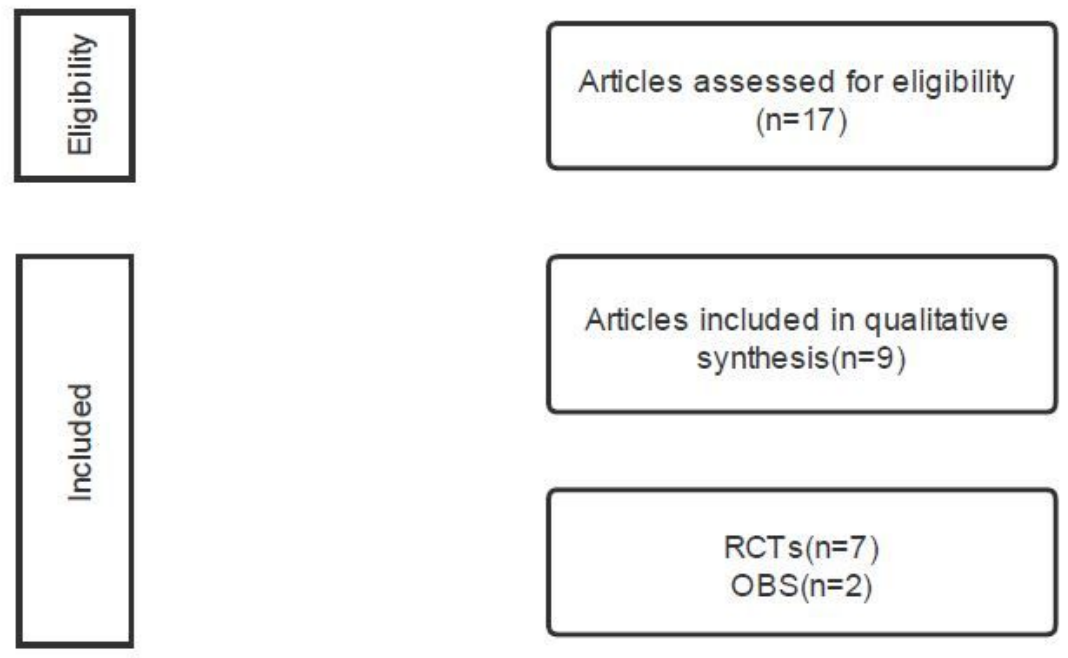

\section{Articles excluded}

Not include outcomes of interest $(n=3)$

Clinical trials have been reported $(n=2)$

No applicable data $(n=3)$

\section{Figure 1}

Flowchart of study selection. 
A

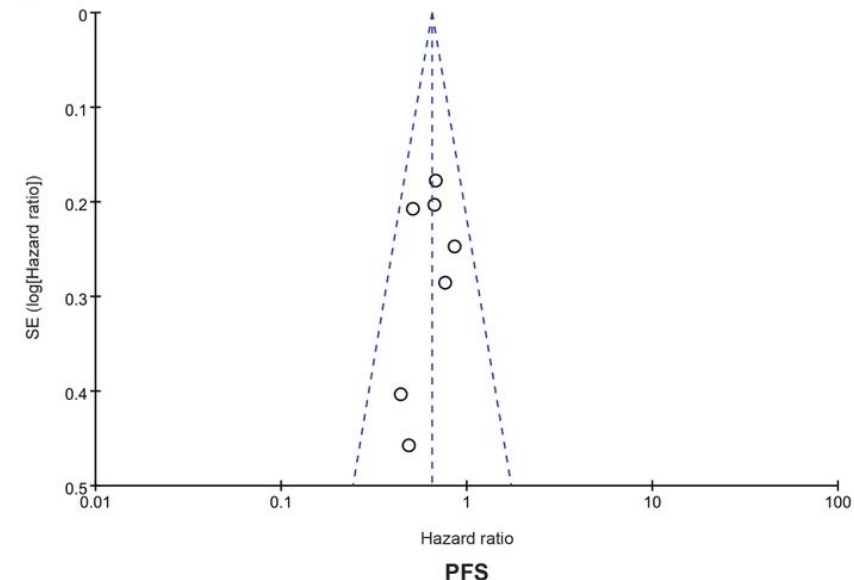

B

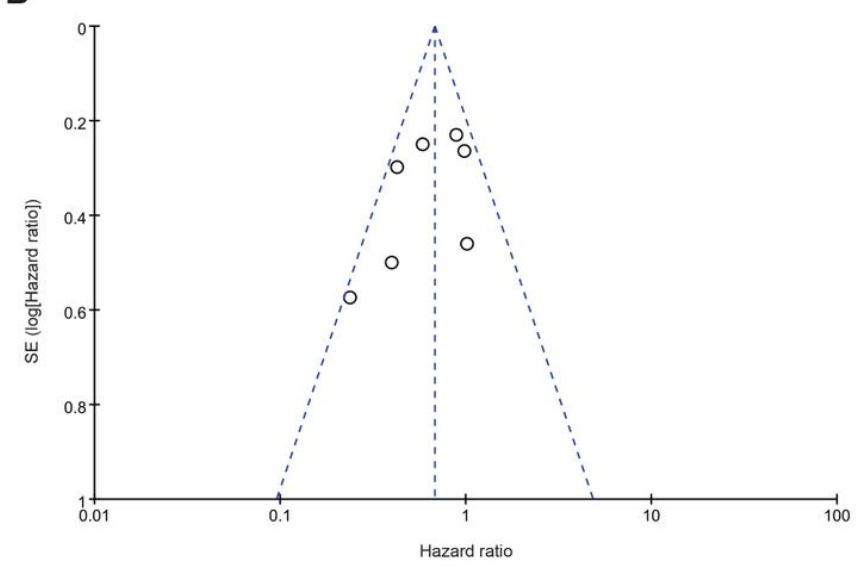

os

Figure 2

\section{Figure 2}

Funnel plots for assessing publication bias. (A) Funnel plot for progression-free survival. (B) Funnel plot for overall survival. PFS, progression-free survival; OS, overall survival. 
A

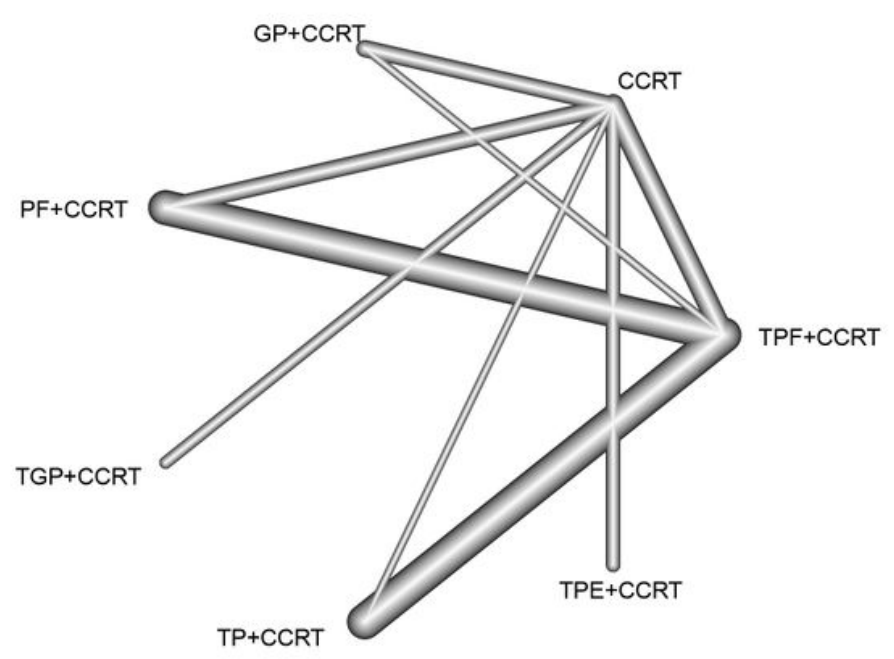

PFS
B

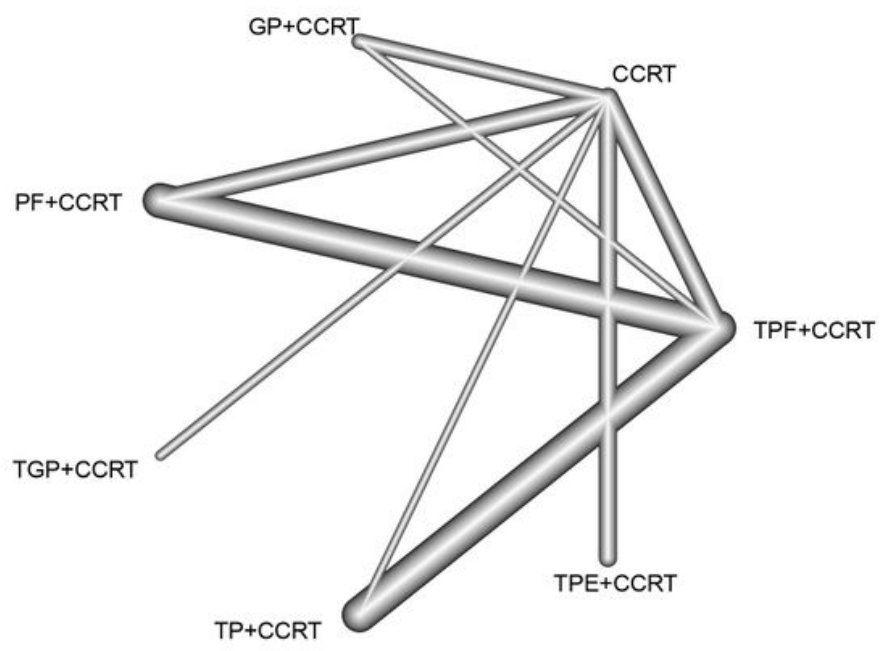

os

\section{Figure 3}

\section{Figure 3}

Evidence network of enrolled studies. (A) Evidence network for PFS. (B) Evidence network for OS. PFS, progression-free survival; OS, overall survival. 
A

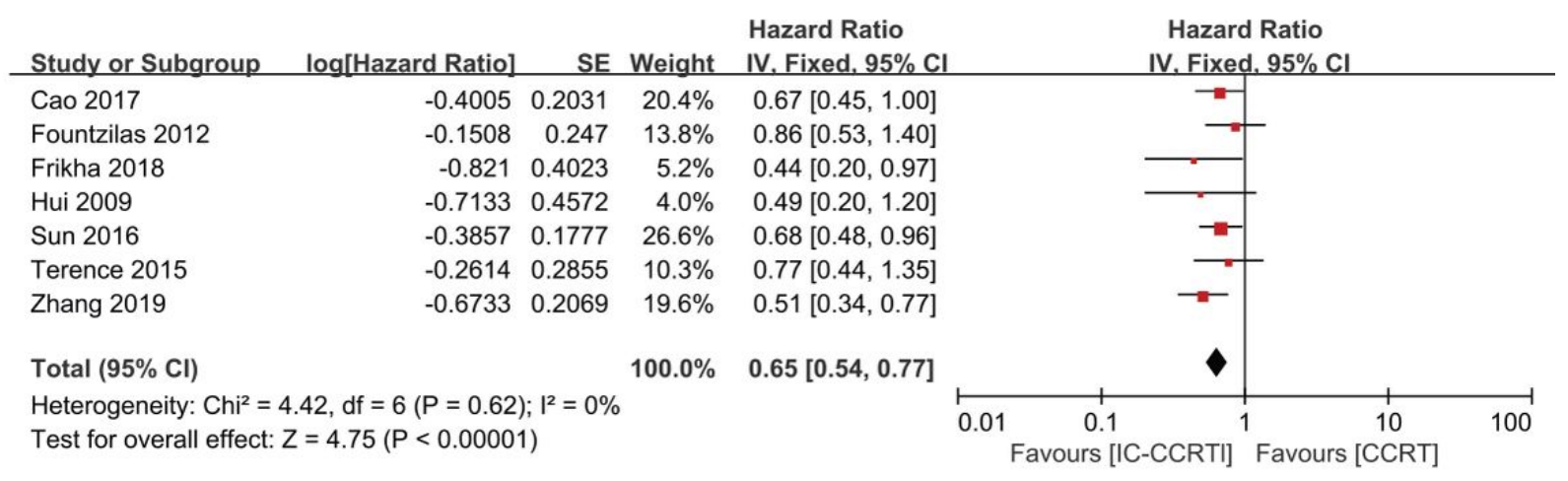

B

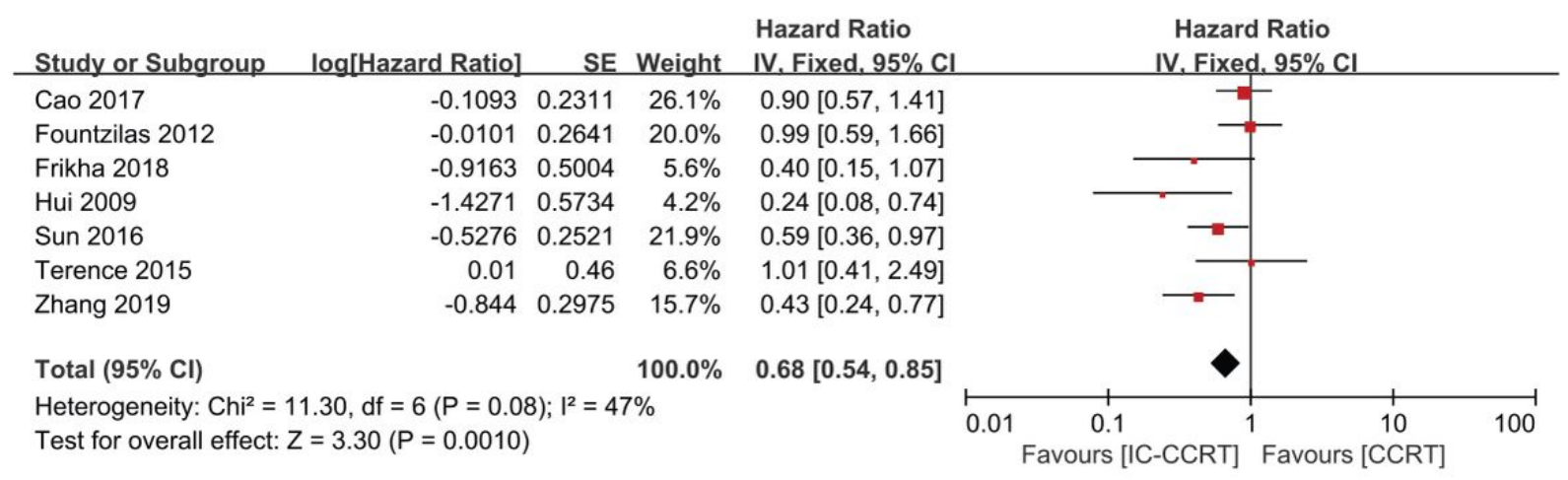

\section{Figure 4}

\section{Figure 4}

Forest plots of hazard ratio (HR) for clinical outcomes in conventional meta-analysis. (A) HR for PFS. (B) HR for OS. HR, hazard ratio; PFS, progression-free survival; OS, overall survival. 
A

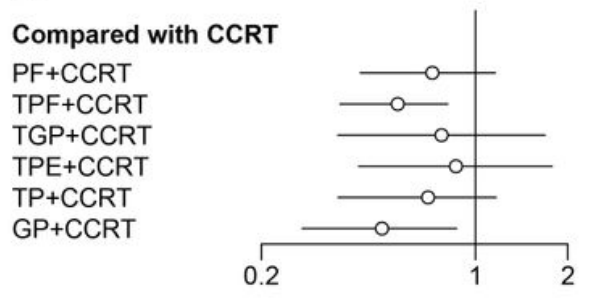

B

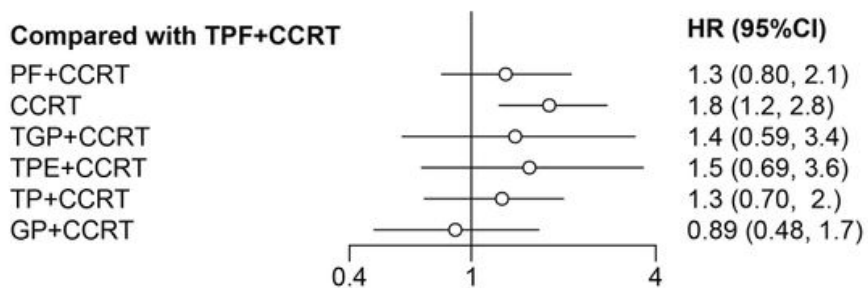

HR $(95 \% \mathrm{Cl})$

$0.72(0.42,1.2)$

$0.56(0.36,0.81)$

$0.77(0.36,1.7)$

$0.86(0.42,1.8)$

$0.70(0.36,1.2)$

$0.50(0.27,0.87)$
C

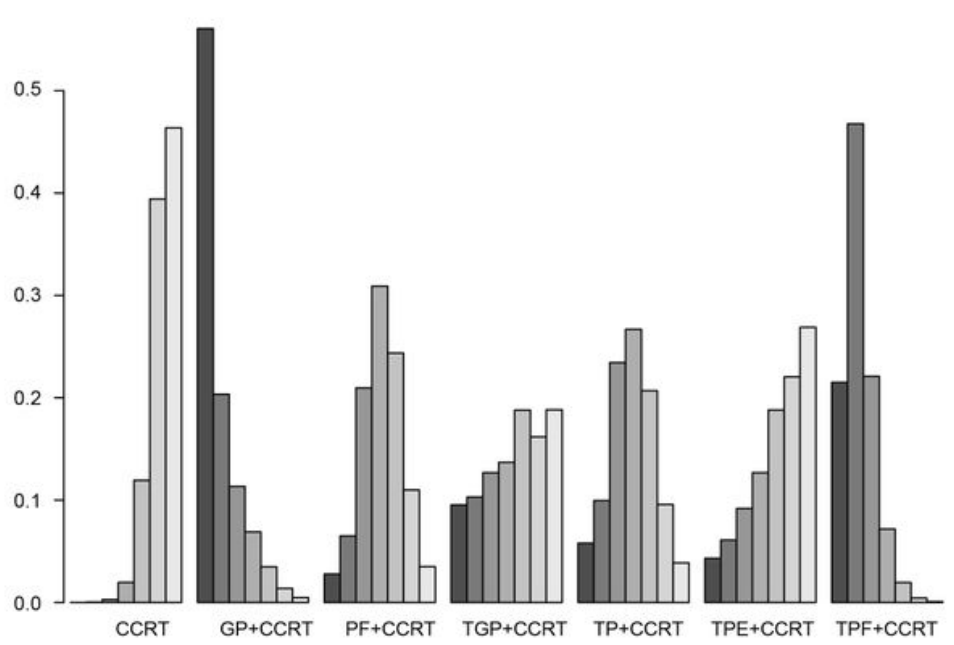

\section{Figure 5}

\section{Figure 5}

Forest plot and rank probability plot of HR for PFS in network meta-analysis. (A) Forest plot of HR of IC+CCRT versus CCRT. (B) Forest plot of HR of other regimens versus TPF+CCRT. (C) Rank probability of HR of IC+CCRT versus CCRT. The comparable effect was shown by the height of bar, with the highest bar located in far left meaning favorable. CCRT, concurrent chemoradiotherapy; HR, hazard ratio; PFS, progression-free survival.

A

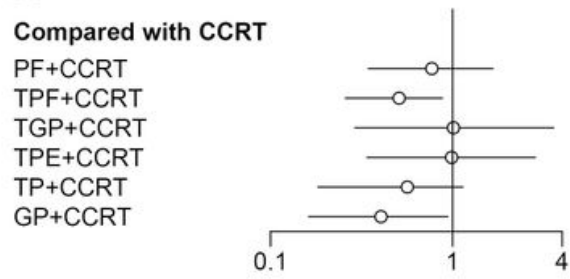

B

Compared with TPF+CCRT PF+CCRT CCRT TGP+CCRT

TPE+CCRT TP+CCRT $\mathrm{GP}+\mathrm{CCRT}$

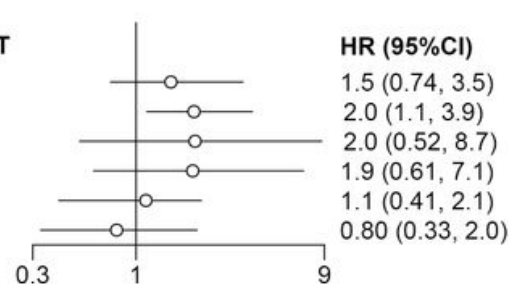

C

$\mathrm{HR}(95 \% \mathrm{Cl})$

$0.77(0.34,1.7)$

$0.51(0.26,0.88)$

$1.0(0.29,3.6)$

$0.99(0.34,2.9)$

$0.56(0.18,1.1)$

$0.40(0.16,0.94)$

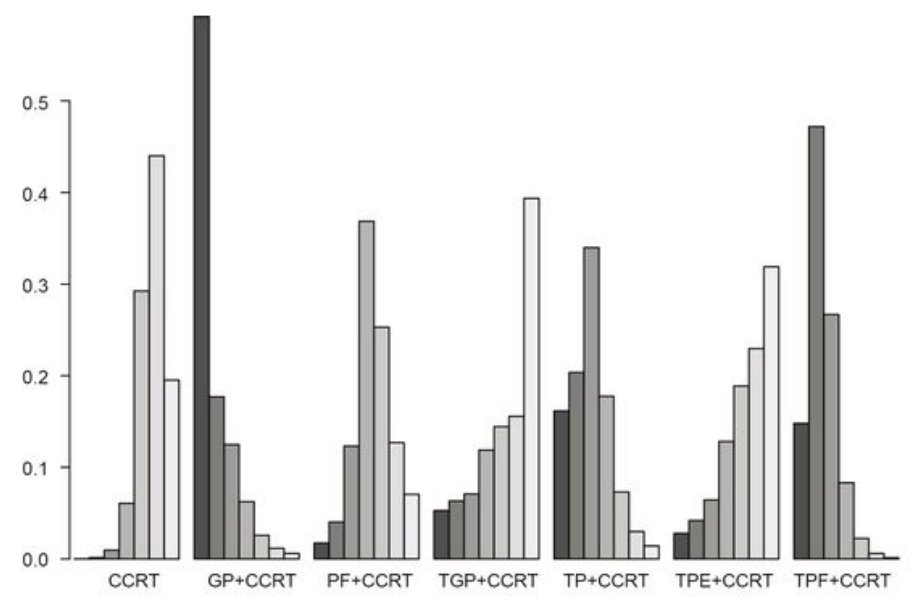

Figure 6

\section{Figure 6}

Forest plot and rank probability plot of HR for OS in network meta-analysis. (A) Forest plot of HR of IC+CCRT versus CCRT. (B) Forest plot of HR of other regimens versus TPF+CCRT. (C) Rank probability of HR of IC+CCRT versus CCRT. The comparable effect was shown by the height of bar, with the highest bar located in far left meaning favorable. CCRT, concurrent chemoradiotherapy; HR, hazard ratio; OS, overall survival. 
A

Compared with CCRT

$\mathrm{PF}+\mathrm{CCRT}$

TPF+CCRT

$\mathrm{GP}+\mathrm{CCRT}$

TGP+CCRT

TP+CCRT

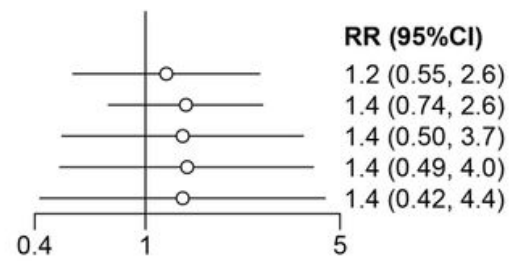

B

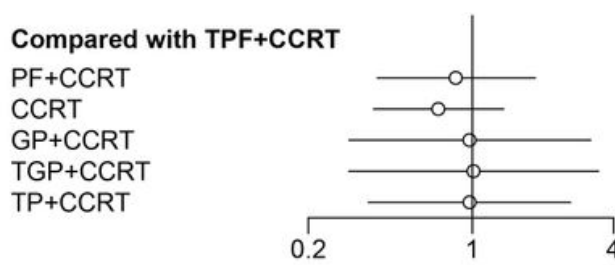

C

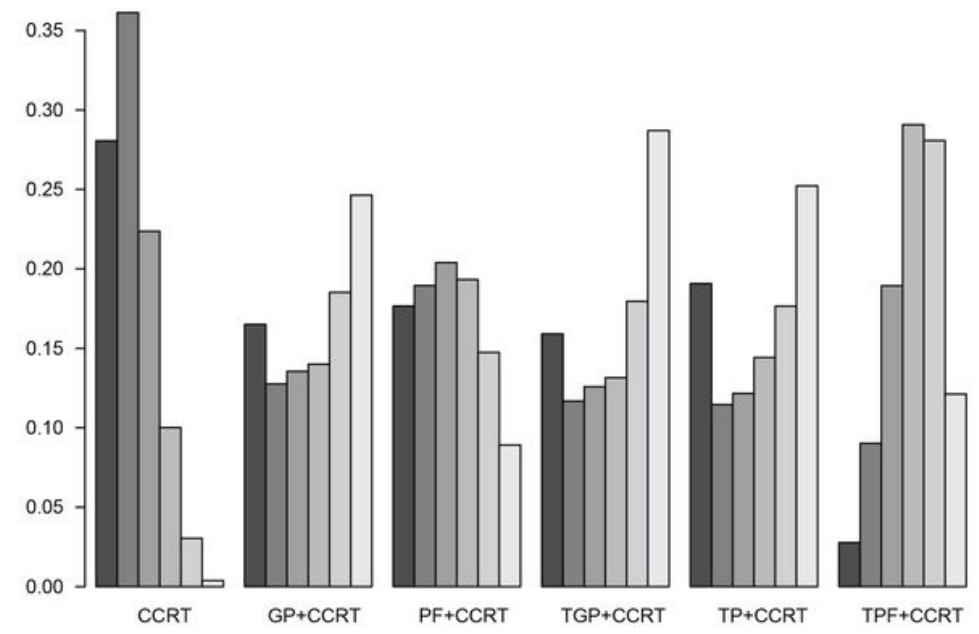

\section{Figure 7}

\section{Figure 7}

Forest plot and rank probability plot of RR for the incidences of $\geq$ grade 3 adverse events in network meta-analysis. (A) Forest plot of RR of IC+CCRT versus CCRT. (B) Forest plot of RR of other regimens versus TPF+CCRT. (C) Rank probability of RR of IC+CCRT versus CCRT. The comparable effect was shown by the height of bar, with the highest bar located in far left meaning favorable. CCRT, concurrent chemoradiotherapy; RR, risk ratio; AE, adverse event. 


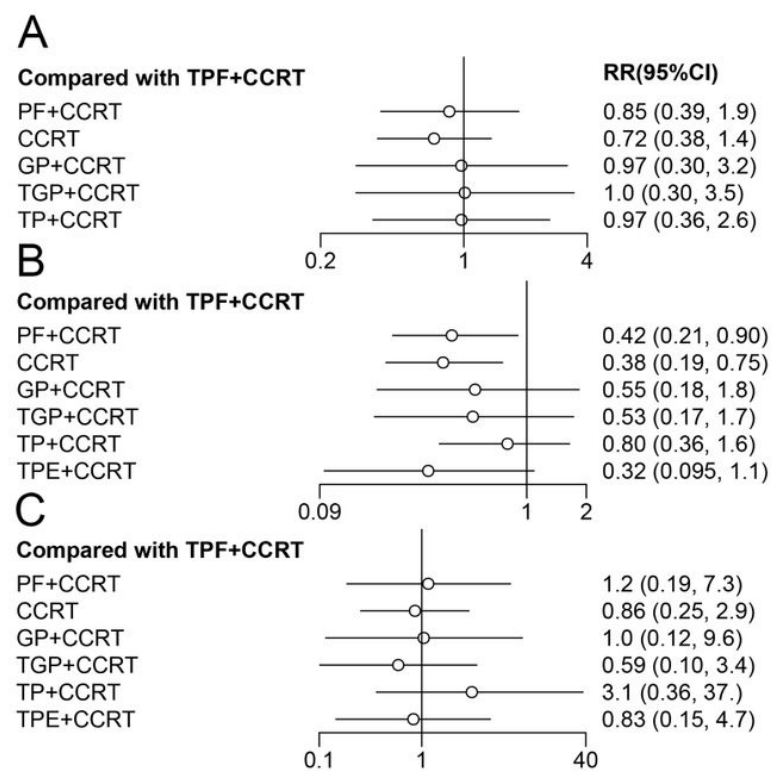

\section{Figure 8}

Forest plots of RR for incidence of $\geq$ grade 3 AEs. (A) Overall available $\geq$ grade 3 AEs. (B) $\geq$ grade 3 leukopenia. (C) $\geq$ grade 3 mucositis. CCRT, concurrent chemoradiotherapy; $R R$, risk ratio; $A E$, adverse event.

\section{Supplementary Files}

This is a list of supplementary files associated with this preprint. Click to download.

- Figures1.pdf

- Figures2.pdf

- Figures3.pdf

- Figures4.pdf

- Figures5.pdf

- Figures6.pdf 